\title{
An Atypical Peri-Prosthetic Femoral Fracture Secondary to Bisphosphonate Use - The Challenges of Surgical Management
}

\author{
Ashraf Awad*, J Evans, T Woodacre and S Blake \\ South Devon Health Care Foundation Trust, Torbay Hospital, UK
}

Submission: February 08, 2018; Published: March 08, 2018

*Corresponding author: Ashraf Awad, South Devon Health Care Foundation Trust, Torbay Hospital, England, UK,

Email: dr_ashrafawad@yahoo.co.uk

\begin{abstract}
We describe a case of an atypical peri-prosthetic femoral fracture around an un-cemented total hip replacement in a 73 year-old patient, thought to be secondary to bisphosphonate use. The challenges associated with fixation of these fractures are demonstrated with a failed prophylactic fixation requiring complex revision surgery.
\end{abstract}

\section{Background}

Atypical femoral fractures have been described as a potential complication of bisphosphonate use in a number of studies over the last decade. There is no definite agreed mechanism as to the pathogenesis of these fractures; however there are a number of theories. Suppression of bone turnover is thought by many to be the main mode of action although mineral distribution, collagen maturity and micro-damage accumulation are some of the other theories [1]. The long half-life of these drugs (up to 10 years) has also been identified as a contributing factor as long lasting inhibition of bone re-modelling [2] preventing the healing of "micro-cracks" causing clinically apparent stress fractures in areas with high mechanical load [3]. The Osteoporosis Clinical Guideline for prevention and treatment, executive summary updated May 2013 [4] describe some of the risk assessment tools and treatment regimes in pharmacological treatment of osteoporosis. It makes reference to intra-medullary fixation being advised in treatment of these fractures and this is supported by a paper by Egol et al. [5].

Regular bisphosphonate use has additionally been reported to reduce post-operative bone resorption following cement-less THR [6,7]. Several case reports have described the difficulties encountered with operative management of atypical femoral fractures, but there is no report that we are aware of as to how these challenges become more problematic in a peri-prosthetic fracture. As the association between bisphosphonate use and atypical femoral fractures and thus diagnosis/incidence increases, one could expect to see more peri-prosthetic atypical femoral fractures described. A 2012 case report by Cross et al. [8] describes the concurrent use of teriparatide in the achievement of union in the only other described periprosthetic bisphosphonate related atypical fracture and no refracture has been reported. The Vancouver classification system for peri-prosthetic THR fractures [9] first described in 1977 is still widely used when describing or planning the management of peri-prosthetic fractures. We present a case highlighting the difficulties in the surgical management of peri-prosthetic atypical femoral fractures and how this should be taken into consideration during operative planning.

\section{Case Presentation}

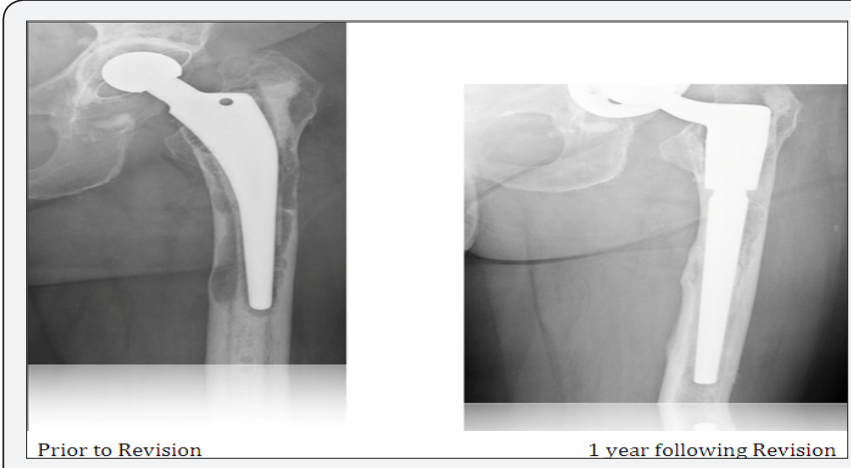

Figure 1: Radiographs showing appearance before and after first Revision (2009).

A 73 year-old female patient underwent an elective Total Hip Replacement (THR) in 1997. In 2008 she was diagnosed with osteoporosis and started on Alendronic Acid 70mg orally once weekly and daily Adcal D3. One year after starting bisphosphonate therapy she was noted to have developed unrelated aseptic loosening of her THR and underwent a 


\section{Orthopedics and Rheumatology Open Access Journal}

relatively routine revision THR. At the time of revision extensive femoral bone loss was noted and this was managed successfully with a combination of Cone Conical Restoration stem (Stryker) and focal femoral bone grafting (Figure 1). Short term follow up revealed excellent function with good reconstitution of femoral bone stock.

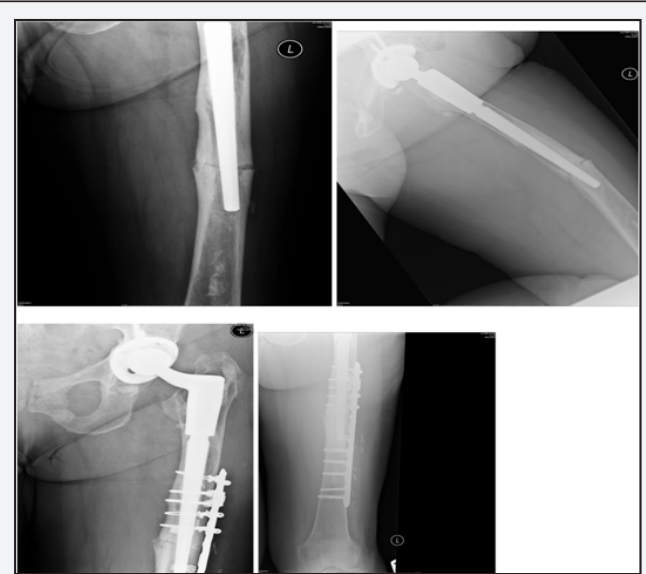

Figure 2: Minimally displaced peri-prosthetic fracture and subsequent fixation (January 2012).

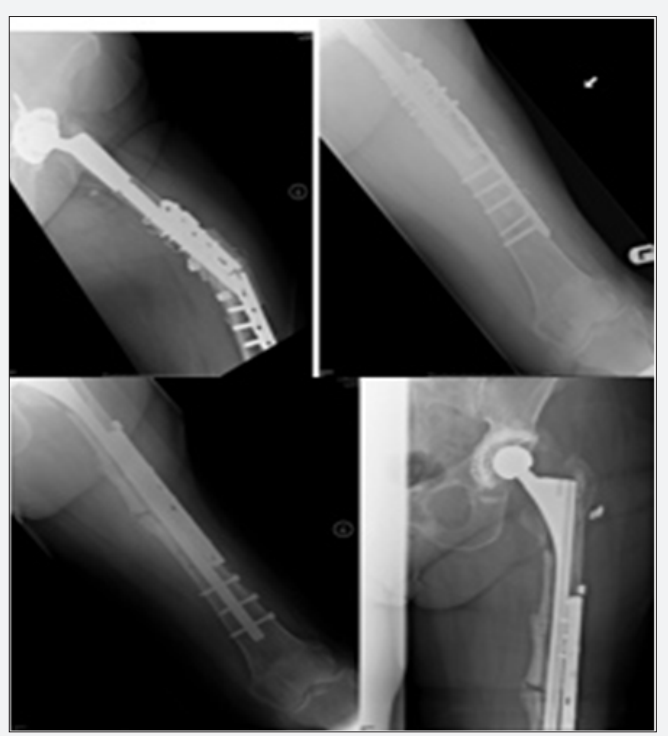

Figure 3: Subsequent peri-prosthetic fracture and metalwork failure. (April 2012) and subsequent final fixation using long distally locked stem following metalwork failure and periprosthetic fracture (April 2012).

Two years following revision, at routine review, the patient complained of mid thigh pain on the operated side. Radiographs taken at this point revealed an atypical appearance of femoral cortices distal to the previously noted femoral bone loss. A bone scan revealed increased tracer uptake at the new site of suspected bone pathology, representing increased bone turnover. These images were compared to a bone scan taken prior to starting bisphosphonate therapy and it was confirmed that the area of high uptake had developed since commencement of alendronic acid. Subsequent plain radiographs revealed a minimally displaced peri-prosthetic fracture (Figure 2). Fixation was completed at this time in line with recommendations for a Vancouver $C$ fracture using a lateral plate and cable construct and anterior strut graft (Figure 2). The patient re-presented 3 months later with an atraumatic peri-prosthetic fracture and metalwork failure (Figure 3). This subsequent peri-prosthetic fracture was far more challenging to manage, requiring bypassing the fracture site with a revised long THR with a distally locked stem, lateral plating and anterior strut grafting, and cabling of a proximal femoral fracture occurring at revision (Figure 3 ). One year following second revision fracture union has still not occurred (Figure 4). The patient is still symptomatic and currently awaiting proximal femoral replacement with excision of the pathological bone.

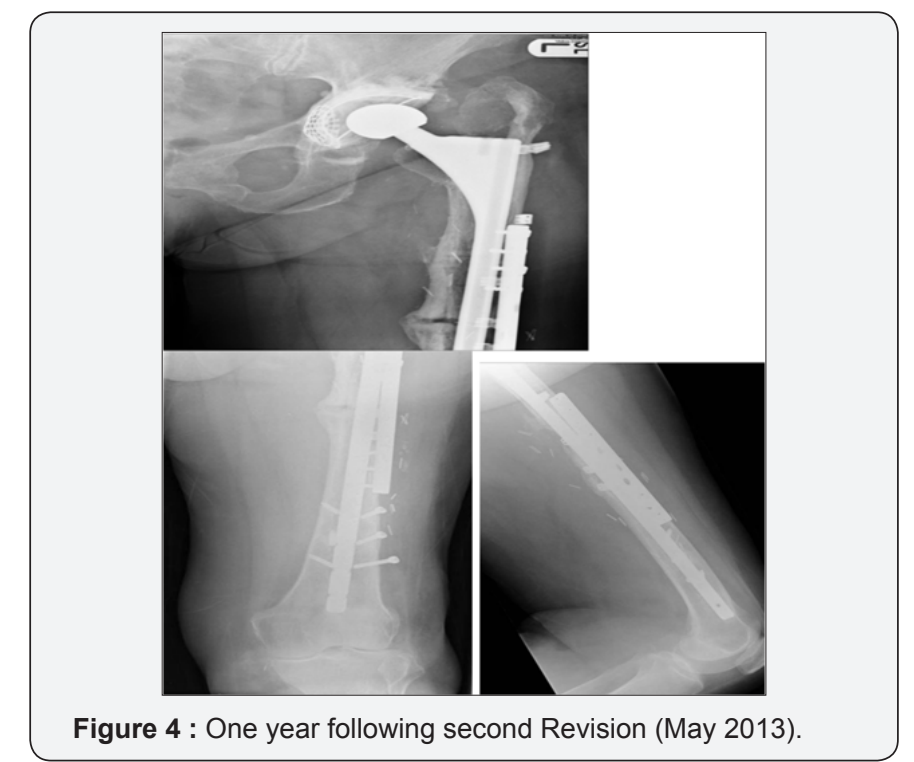

\section{Discussion}

We believe this case serves as an example of how the Vancouver classification of peri-prosthetic fractures is not ideal at guiding the management of bisphosphonate related atypical femoral fractures. We would recommend bypassing the fracture site with a revised intramedullary prosthesis as part of initial management regardless of apparent proximal bone stock although further studies will be required to fully support this.

\section{References}

1. Compton J (2011) Pathophysiology of atypical femoral fractures and osteonecrosis of the jaw. Osteoporosis Int 22: 2951-2961.

2. Odvina CV, Zerwekh JE, Rao DS, Maalouf N, Gottschalk FA (2005) Severely suppressed bone turnover, a potential complication of alendronate therapy. J Clin Endocrinol Metab 90(3): 1294-1301.

3. Meier RP, Perneger TV, Stern R, Rizzoli R, Peter RE (2012) Increasing Occurrence of Atypical Femoral Fractures Associated with Bisphosphonate Use. Arch Intern Med 172(12): 930-936.

4. Osteoporosis (2013) Clinical Guideline for prevention and treatment, Executive Summary. National Osteoporosis Guideline Group (NOGG).

5. Egol KA, Park JH, Rosenberg ZS, Peck V, Tejwani NC (2013) Healing Delayed But Generally Reliable After Bisphosphonate-associated Complete Femur Fractures Treated with IM Nails. Clin Orthop Relat Res 472(9): 2728-2734. 
6. Sköldenberg OG, Salemyr MO, Bodén HS, Ahl TE, Adolphson PY (2011) The effect of weekly risedronate on periprosthetic bone resorption following total hip arthroplasty: a randomized, double-blind, placebocontrolled trial. J Bone Joint Surg Am 93(20): 1857-1864.

7. Yamasaki S, Masuhara K, Yamaguchi K, Nakai T, Fuji T, et al. (2007) Risedronate reduces postoperative bone resorption after cementless total hip arthroplasty. Int J Surg 18(7): 1009-1015.
8. Cross MB, Nam D, van der Meulen MC, Bostrom MP (2012) A rare case of a bisphosphonate-induced peri-prosthetic femoral fracture. J Bone Joint Surg Br 94(7): 994-997.

9. Khan MA, O'Driscoll M (1977) Fractures of the femur during total hip replacement and their management. J Bone Joint Surg Br 59(1): 36-41.

\section{Your next submission with Juniper Publishers will reach you the below assets}

- Quality Editorial service

- Swift Peer Review

- Reprints availability

- E-prints Service

- Manuscript Podcast for convenient understanding

- Global attainment for your research

- Manuscript accessibility in different formats

( Pdf, E-pub, Full Text, Audio)

- Unceasing customer service

Track the below URL for one-step submission https://juniperpublishers.com/online-submission.php 